\title{
EXAFS Analysis of Zr-Based Quasicrystals
}

\author{
A. P. Menushenkov ${ }^{a}$, O. V. Kashurnikova ${ }^{a}$, R. V. Chernikov ${ }^{a}$, \\ K. V. Klementiev ${ }^{b}$, G. Kh. Panova ${ }^{c}$, and A. A. Shikov ${ }^{c}$ \\ ${ }^{a}$ Moscow Engineering Physics Institute, Kashirskoe sh. 31, Moscow, 115409 Russia \\ e-mail: menushen@htsc.mephi.ru \\ ${ }^{b}$ ALBA CELLS, 08193 Bellaterra, Barcelona, Spain. \\ ${ }^{c}$ Russian Research Centre Kurchatov Institute, pl. Akademika Kurchatova 1, Moscow, 123182 Russia
}

\begin{abstract}
The character of transformation of the local structure of zirconium and palladium atoms in $\mathrm{Zr}_{70} \mathrm{Pd}_{30}$ binary alloy at a transition from the amorphous state to the quasicrystalline and crystalline states and in $\mathrm{Zr}_{70} \mathrm{Be}_{30}$ and $\mathrm{Zr}_{80} \mathrm{Pt}_{20}$ binary alloys at a transition from the amorphous to the quasicrystalline state have been investigated by extended X-ray absorption fine-structure (EXAFS) spectroscopy and X-ray diffraction. The parameters of the zirconium, palladium, and platinum local structure are determined, and the general features and differences in the local atomic rearrangement during formation of icosahedral clusters around zirconium atoms in these three compounds are established.
\end{abstract}

DOI: $10.3103 / \mathrm{S} 1062873808100389$

The quasicrystalline state of matter, which is intermediate between the amorphous and crystalline states [1], has a number of unusual properties, such as high microhardness; strength; low wetting; and some peculiar electronic properties, which are related to the existence of a pseudogap in the electronic spectrum. Therefore, quasicrystals can be widely and effectively used as additives modifying the surface properties of metals and alloys, non-stick coatings, antifriction additives, etc. The quasicrystalline state of $\mathrm{Zr}_{70} \mathrm{Pd}_{30}, \mathrm{Zr}_{70} \mathrm{Be}_{30}$, and $\mathrm{Zr}_{80} \mathrm{Pt}_{20}$ binary alloys is formed in spite of the empirical rules of glass formation, established for $\mathrm{Zr}$ based alloys; in particular, the multicomponent composition rule [2]. Hence, the specific features of their local atomic structure are of great interest.

In this paper, we report the results of the investigation of the changes in the local structure of Zr-based binary alloys at the phase transitions from the amorphous to the quasicrystalline state and from the crystalline to the quasicrystalline state (for $\mathrm{Zr}_{70} \mathrm{Pd}_{30}$ ).

The $\mathrm{Zr}_{70} \mathrm{Pd}_{30}$ alloy was prepared at the Russian Research Centre Kurchatov Institute by the technique described in [3], from electrolytically pure zirconium (99.99\%) and pure palladium (99.96\%). Polycrystalline $\mathrm{Zr}_{70} \mathrm{Pd}_{30}$ samples were grown in an induction furnace in argon. To obtain amorphous samples, starting elements were placed in a boron nitride ampoule, melted in the induction furnace under low argon pressure, and rapidly (at a rate of $10^{6} \mathrm{~K} / \mathrm{s}$ ) quenched from the liquid state onto the outer surface of a rotating copper cylinder. Quasicrystalline samples were prepared by annealing the thus obtained amorphous ribbons with a width of $1.5-2 \mathrm{~mm}$ and a thickness of $\sim 30 \mu \mathrm{m}$ in a helium gas flow through a quartz tube placed in a muffle furnace.
The preparation conditions for the most perfect icosahedral sample was optimized by annealing at several temperatures (740 and $760 \mathrm{~K}$ ) with subsequent rapid quenching. The structure of the samples and the effect of annealing on their state were analyzed using a DRON-2 diffractometer in $\mathrm{Cu} K_{\alpha}$ radiation. The phase analysis was performed on the basis of the X-ray diffraction patterns.

According to the X-ray diffraction data, the crystalline phase has the symmetry group $14 / \mathrm{mmm}$ with the lattice parameters $a=3.306 \AA$ and $c=10.894 \AA$. The $\mathrm{X}$-ray diffraction analysis of the quasicrystalline phase according to Bansel [4] showed the presence of an icosahedral structure with the hypercubic lattice parameter $a=7.624 \AA$. At an annealing temperature of $760 \mathrm{~K}$, the quality of the quasicrystalline phase was higher; however, with a further increase in temperature and annealing time, crystalline phase began to form in the samples. Annealing at $873 \mathrm{~K}$ led to complete recovery of the crystal structure.

Amorphous and quasicrystalline $\mathrm{Zr}_{80} \mathrm{Pt}_{20}$ and $\mathrm{Zr}_{70} \mathrm{Be}_{30}$ samples were prepared similarly. To obtain quasicrystalline samples, amorphous $\mathrm{Zr}_{80} \mathrm{Pt}_{20}$ and $\mathrm{Zr}_{70} \mathrm{Be}_{30}$ ribbons were annealed for $20 \mathrm{~min}$ at 600 and $650 \mathrm{~K}$, respectively.

Extended X-ray absorption fine-structure (EXAFS) measurements were performed above the $K$ absorption edges of zirconium $(17998 \mathrm{eV})$ and palladium $(24350 \mathrm{eV})$ and the $L_{\mathrm{III}}$ absorption edge of platinum $(11564 \mathrm{eV})$ on the $A 1$ line at HASYLAB/DESY (Hamburg, Germany) at temperatures of 10,77 , and $300 \mathrm{~K}$. The EXAFS spectra of thick single-crystal samples were measured with the use of the fluorescent technique, while the amorphous ribbons and quasicrystalline powders were ana- 


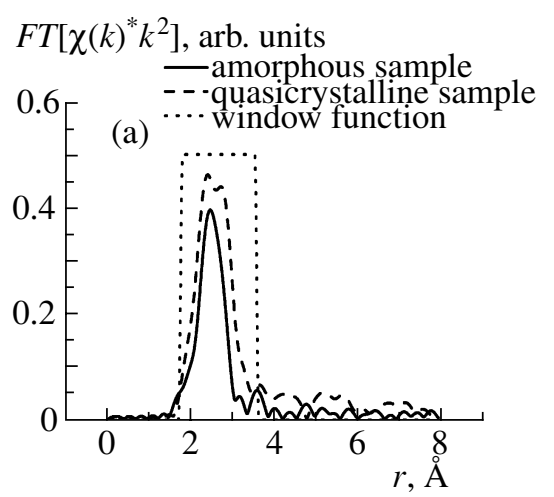

- amorphous sample - - - quasicrystalline sample

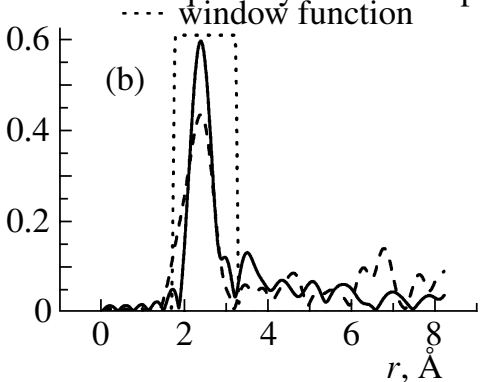

Fig. 1. Moduli of the Fourier transforms of the EXAFS function $\chi(k) k^{2}$ for the quasicrystalline and amorphous $\mathrm{Zr}_{70} \mathrm{Pd}_{30}$ samples, measured at $T=10 \mathrm{~K}$ above the $K$-absorption edges of (a) zirconium and (b) palladium. The rectangles show the inverse Fourier transform windows for selecting the contribution from the nearest zirconium and palladium environment.

lyzed in transmission. The EXAFS spectra were processed using the VIPER software package [5] using the standard selection procedure and Fourier analysis of the

Table 1. Parameters of the local structure of zirconium and palladium atoms in $\mathrm{Zr}_{70} \mathrm{Pd}_{30}$ in the quasicrystalline and amorphous states: the coordination number $N$, the interatomic distance $R$, and the Debye-Waller factor $\sigma^{2}$

\begin{tabular}{|c|c|c|c|c|}
\hline $\begin{array}{l}\text { Absorption } \\
\text { edge }\end{array}$ & $\begin{array}{c}\text { Type } \\
\text { of atom }\end{array}$ & $N$ & $R, \AA$ & $\sigma^{2}, \AA^{2}$ \\
\hline \multicolumn{5}{|c|}{ Quasicrystal $\mathrm{Zr}_{70} \mathrm{Pd}_{30}$} \\
\hline \multirow{3}{*}{$\begin{array}{l}K-\mathrm{Zr} \\
\text { model } 1\end{array}$} & $\mathrm{Pd}$ & $1.6 \pm 1.0$ & 2.70 & 0.0071 \\
\hline & $\operatorname{Zr}(1)$ & $2.35 \pm 1.0$ & 2.95 & 0.0200 \\
\hline & $\operatorname{Zr}(2)$ & $7.4 \pm 1.0$ & 3.18 & 0.0151 \\
\hline \multirow{2}{*}{$\begin{array}{l}K-\mathrm{Zr}, \\
\text { model } 2\end{array}$} & $\mathrm{Pd}$ & $1.1 \pm 1.0$ & 2.70 & 0.0059 \\
\hline & $\mathrm{Zr}$ & $6.4 \pm 3.0$ & 3.18 & 0.0147 \\
\hline$K-\mathrm{Pd}$ & $\mathrm{Zr}$ & $3.9 \pm 1.0$ & 2.72 & 0.0122 \\
\hline \multicolumn{5}{|c|}{ Amorphous phase $\mathrm{Zr}_{70} \mathrm{Pd}_{30}$} \\
\hline \multirow{2}{*}{$K-\mathrm{Zr}$} & $\mathrm{Pd}$ & $1.3 \pm 1.0$ & 2.73 & 0.0080 \\
\hline & $\mathrm{Zr}$ & $2.3 \pm 1.0$ & 3.16 & 0.0124 \\
\hline \multirow{2}{*}{$K-\mathrm{Pd}$} & $\mathrm{Zr}$ & $2.9 \pm 1.0$ & 2.73 & 0.0077 \\
\hline & $\mathrm{Pd}$ & $2.3 \pm 1.0$ & 2.83 & 0.0120 \\
\hline
\end{tabular}

EXAFS function $\chi(k)$; the amplitudes $f_{j}(\pi, k)$ and backscattering phases $\phi_{j}(k)$ were calculated using the FEFF8.20 program [6].

The EXAFS analysis of the local structure of zirconium and palladium in a $\mathrm{Zr}_{70} \mathrm{Pd}_{30}$ single crystal revealed that its similarity to the structure of the $\mathrm{Zr}_{2} \mathrm{Pd}$ analog crystal [7], which was used to calculate the amplitudes and phases of this alloy in all three states. Figures $1 \mathrm{a}$ and $1 \mathrm{~b}$ show the moduli of the Fourier transforms of the EXAFS functions for the quasicrystalline and amorphous $\mathrm{Zr}_{70} \mathrm{Pd}_{30}$ phases, measured above the $K$ absorption edges of $\mathrm{Zr}$ and $\mathrm{Pd}$, respectively. The shape of the Fourier transform modulus for the EXAFS function of a quasicrystal for the $\mathrm{Zr} K$ edge significantly differs from the Fourier transform modulus for the amorphous sample, which indicates the difference in the local structure of zirconium in the quasicrystalline phase from the structure in the amorphous state in view of the formation of icosahedral ordering; however, for the $\mathrm{Pd} K$ edge, the difference is not observed.

The results of the simulation of the EXAFS spectra for $\mathrm{Zr}_{70} \mathrm{Pd}_{30}$ are listed in Table 1; ordering around zirconium was modeled in two ways. The difference between the models is the introduction of an additional coordination sphere from one to two $\mathrm{Zr}$ atoms at a distance of $2.95 \AA$ A. Such a model provided a characteristic total coordination number of 11.5 atoms and somewhat more exactly described the experimental spectrum. In this case, the structure of the icosahedral cluster is distorted: most of $\mathrm{Pd}$ and $\mathrm{Zr}$ atoms are at distances of 2.70 and $3.18 \AA$, respectively; these values are in good agreement with the electron diffraction data [8]. The noted

Table 2. Parameters of the local structure of $\mathrm{Zr}_{80} \mathrm{Pt}_{20}$ and $\mathrm{Zr}_{70} \mathrm{Be}_{30}$ in the quasicrystalline and amorphous states: the coordination number $N$, the interatomic distance $R$, and the Debye-Waller factor $\sigma^{2}$

\begin{tabular}{l|l|c|c|c}
\hline $\begin{array}{c}\text { Absorp- } \\
\text { tion edge }\end{array}$ & $\begin{array}{c}\text { Type } \\
\text { of atom }\end{array}$ & $N$ & $R, \AA$ & $\sigma^{2}, \AA^{2}$ \\
\hline \multicolumn{5}{c}{ Quasicrystal $\mathrm{Zr}_{80} \mathrm{Pt}_{20}$} \\
\hline \multirow{3}{*}{$K-\mathrm{Zr}$} & $\mathrm{Zr}-\mathrm{Pt}$ & $1.6 \pm 1.2$ & $2.78 \pm 0.09$ & 0.0203 \\
\cline { 2 - 5 } & $\mathrm{Zr}-\mathrm{Zr}(1)$ & 0.7 & $2.88 \pm 0.02$ & 0.0080 \\
\cline { 2 - 5 } $\mathrm{Zr}-\mathrm{Zr}(2)$ & $5.8 \pm 2.3$ & $3.18 \pm 0.02$ & 0.0182 \\
\hline $\mathrm{L}_{3}-\mathrm{Pt}$ & $\mathrm{Pt}-\mathrm{Zr}$ & 3.6 & 2.70 & 0.0103 \\
\hline \multicolumn{5}{c}{$\mathrm{Amorphous} \mathrm{phase} \mathrm{Zr}_{80} \mathrm{Pt}_{20}$} \\
\hline \multirow{5}{*}{$K-\mathrm{Zr}$} & $\mathrm{Zr}-\mathrm{Pt}$ & 0.45 & 2.79 & 0.0036 \\
\cline { 2 - 5 } & $\mathrm{Zr}-\mathrm{Zr}$ & 2.36 & 3.17 & 0.0130 \\
\hline $\mathrm{L}_{3}-\mathrm{Pt}$ & $\mathrm{Pt}-\mathrm{Zr}$ & 2.8 & 2.73 & 0.0078 \\
\hline \multicolumn{5}{c}{ Quasicrystal $\mathrm{Zr}_{70} \mathrm{Be}_{30}$} \\
\hline \multirow{2}{*}{$K-\mathrm{Zr}$} & $\mathrm{Zr}-\mathrm{Zr}(1)$ & $4.0 \pm 3.0$ & $2.93 \pm 0.05$ & 0.0179 \\
\cline { 2 - 5 } & $\mathrm{Zr}-\mathrm{Zr}(2)$ & $10.5 \pm 2.0$ & 3.19 & 0.0123 \\
\hline \multicolumn{6}{c}{$\mathrm{Amorphous}$ phase $\mathrm{Zr}_{70} \mathrm{Be}_{30}$} \\
\hline \multirow{2}{*}{$K-\mathrm{Zr}$} & $\mathrm{Zr}-\mathrm{Be}$ & 2.03 & 2.78 & 0.0060 \\
\cline { 2 - 5 } & $\mathrm{Zr}-\mathrm{Zr}$ & 5.75 & 3.11 & 0.0192 \\
\hline
\end{tabular}



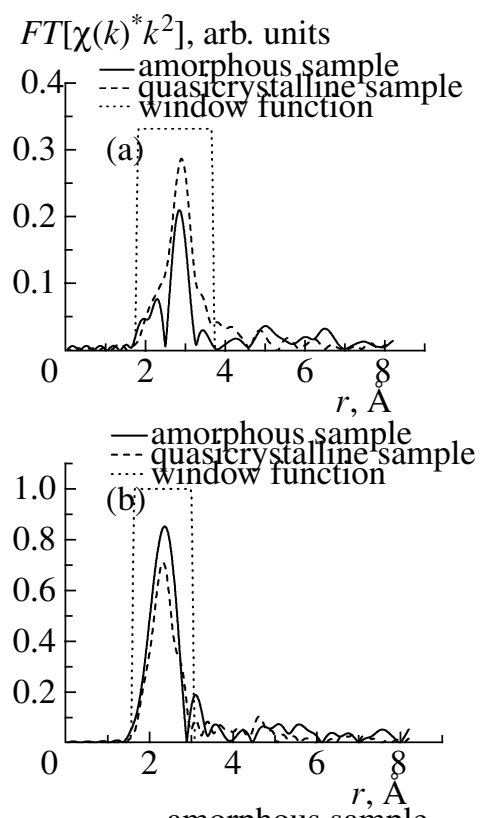

- amorphous sample

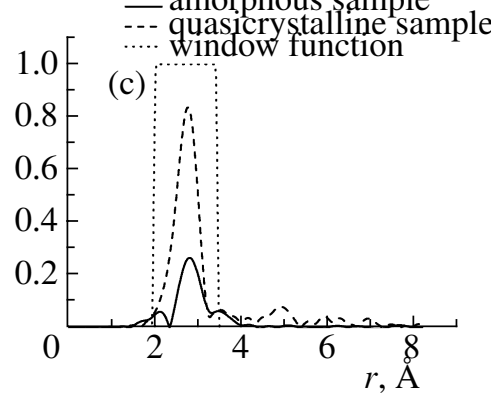

Fig. 2. Moduli of the Fourier transforms of the EXAFS function $\chi(k) k^{2}$ for the quasicrystalline and amorphous (a, b) $\mathrm{Zr}_{80} \mathrm{Pt}_{20}$ samples, measured at $T=77 \mathrm{~K}$ above the $K$ absorption edge of (a) zirconium and (b) platinum, and (c) $\mathrm{Zr}_{70} \mathrm{Be}_{30}$ samples, measured at $T=77 \mathrm{~K}$ above the $\mathrm{Zr}$ $K$-absorption edge. The rectangles show the inverse Fourier transform windows for selecting the contribution from the nearest zirconium and platinum environment.

distortion can be due to the fact that not all zirconium atoms are centers of icosahedral clusters in the quasicrystalline structure, and the EXAFS data reflect the averaged contribution of the local coordination of $\mathrm{Zr}$ atoms occupying different crystallographic positions. The formation of an icosahedral cluster is accompanied by a significant decrease in size of the first coordination spheres of $\mathrm{Zr}$ in comparison with a crystal. Palladium atoms are forced out from the Pd environment in the quasicrystalline phase.

The $\mathrm{Zr}$ local structure in the amorphous phase (Fig. 1a, Table 1) does not exhibit an icosahedral shortrange order, although the electron diffraction data (obtained at sharp focusing of the electron beam into a nanosized spot) indicated the presence of icosahedral ordering regions. EXAFS spectroscopy does not make it possible to select such regions.

The EXAFS spectra of quasicrystalline and amorphous $\mathrm{Zr}_{80} \mathrm{Pt}_{20}$ above the $\mathrm{Zr} K$ - and $\mathrm{Pt} L_{\mathrm{III}}$-absorption edges were processed in the same way as for $\mathrm{Zr}_{70} \mathrm{Pd}_{30}$. The structure of the main peak in the Fourier transform of EXAFS function, measured above the Pt $L_{\mathrm{III}}$-absorption edge for a quasicrystal is the same as the structure of the amorphous phase peak. The results of the simulation of the EXAFS function $\chi(k) k^{2}$ on the basis of the $\beta-\mathrm{ZrPt}$ crystal model are listed in Table 2 . This table contains also the data on simulation of the EXAFS function, measured above the $\mathrm{Zr} K$-absorption edge of $\mathrm{Zr}_{70} \mathrm{Be}_{30}$. A quasicrystal is formed in both cases as for $\mathrm{Zr}_{70} \mathrm{Pd}_{30}$, and correlation of distances is observed. The nearest Pt environment turned out to include only four $\mathrm{Zr}$ atoms, located at a distance of $2.71 \AA$ in the quasicrystalline phase, and three $\mathrm{Zr}$ atoms, located at a distance of $2.70 \AA$ in the amorphous phase; Pt atoms were forced away from the local platinum structure in both cases. This arrangement can be related to the large radius and mass of platinum atoms. Icosahedral coordination is not formed around Pt. In $\mathrm{Zr}_{70} \mathrm{Be}_{30}$, an icosahedral cluster containing only $\mathrm{Zr}$ atoms is formed around zirconium, because $\mathrm{Be}$ atoms has a small radius and mass.

Thus, using EXAFS spectroscopy, we determined the character of local transformations of atoms in $\mathrm{Zr}_{70} \mathrm{Pd}_{30}, \mathrm{Zr}_{80} \mathrm{Pt}_{20}$, and $\mathrm{Zr}_{70} \mathrm{Be}_{30}$ binary alloys during transition to the quasicrystalline state. It is established that the centers of formation of icosahedral clusters in all three alloys are zirconium atoms. The local structure of palladium and platinum atoms is almost the same as in the amorphous phase. The distances to the nearest atoms correlate for these three materials; the differences in the structure are due to the differences in the size and mass of $\mathrm{Pd}, \mathrm{Pt}$, and $\mathrm{Be}$ atoms.

\section{ACKNOWLEDGMENTS}

We are grateful to the HASYLAB Program Committee for the possibility of carrying out experiments on the synchrotron source.

This study was supported by the Russian Foundation for Basic Research, project no. 05-02-16996-a.

\section{REFERENCES}

1. Shechtman, D., Blech, I., Gratias, D., and Cahn, J.W., Phys. Rev. Lett., 1984, vol. 53, p. 1957.

2. Saida, J., Matsushita, M., and Inoue, A., Intermetallics, 2002, vol. 10, p. 1089.

3. Panova, G.Kh., Chernoplekov, N.A., and Shikov, A.A., Fiz. Tverd. Tela (St. Petersburg), 2005, vol. 47, no. 7, p. 1165 [Phys. Solid State (Engl. Transl.), vol. 47, no. 7, p. 1205].

4. Bancel, P.A., Heiney, P.A., Stephens, P.W., et al., Phys. Rev. Lett., 1985, vol. 54, p. 2422.

5. Klementev, K.V., J. Phys. D: Appl. Phys., 2001, vol. 34, p. 209.

6. Newville, M., Ravel, B., Haskel, D., et al., Physica B, 1995, vols. 208-209, p. 495.

7. Nakamura, T., J. Non-Cryst. Solids, 2002, vols. 312314 , p. 517.

8. Takagi, T., Ohkubo, T., Hirotsu, Y., et al., Appl. Phys. Lett., 2001, vol. 79, p. 485. 